\title{
Amelioration of Glucolipotoxicity-Induced Endoplasmic Reticulum Stress by a "Chemical Chaperone" in Human THP-1 Monocytes
}

\author{
Raji Lenin, ${ }^{1}$ Mariawilliam Sneha Maria, ${ }^{1}$ Madhur Agrawal, ${ }^{1}$ Jayashree Balasubramanyam, ${ }^{2}$ \\ Viswanathan Mohan, ${ }^{1}$ and Muthuswamy Balasubramanyam ${ }^{1}$ \\ ${ }^{1}$ Department of Cell and Molecular Biology, Madras Diabetes Research Foundation and Dr. Mohans' Diabetes Specialities Centre, \\ Chennai 600086, India \\ ${ }^{2}$ Centre for Biotechnology, Anna University, Chennai 600025, India
}

Correspondence should be addressed to Muthuswamy Balasubramanyam, balusignal@gmail.com

Received 17 December 2011; Accepted 13 February 2012

Academic Editor: Rangasamy Sampathkumar

Copyright (C) 2012 Raji Lenin et al. This is an open access article distributed under the Creative Commons Attribution License, which permits unrestricted use, distribution, and reproduction in any medium, provided the original work is properly cited.

\begin{abstract}
Chronic ER stress is emerging as a trigger that imbalances a number of systemic and arterial-wall factors and promote atherosclerosis. Macrophage apoptosis within advanced atherosclerotic lesions is also known to increase the risk of atherothrombotic disease. We hypothesize that glucolipotoxicity might mediate monocyte activation and apoptosis through ER stress. Therefore, the aims of this study are (a) to investigate whether glucolipotoxicity could impose ER stress and apoptosis in THP-1 human monocytes and (b) to investigate whether 4-Phenyl butyric acid (PBA), a chemical chaperone could resist the glucolipotoxicity-induced ER stress and apoptosis. Cells subjected to either glucolipotoxicity or tunicamycin exhibited increased ROS generation, gene and protein (PERK, GRP-78, IRE1 $\alpha$, and CHOP) expression of ER stress markers. In addition, these cells showed increased TRPC-6 channel expression and apoptosis as revealed by DNA damage and increased caspase-3 activity. While glucolipotoxicity/tunicamycin increased oxidative stress, ER stress, mRNA expression of TRPC-6, and programmed the THP-1 monocytes towards apoptosis, all these molecular perturbations were resisted by PBA. Since ER stress is one of the underlying causes of monocyte dysfunction in diabetes and atherosclerosis, our study emphasize that chemical chaperones such as PBA could alleviate ER stress and have potential to become novel therapeutics.
\end{abstract}

\section{Introduction}

Cardiovascular complications due to atherosclerotic disease are a frequent cause of morbidity and mortality in patients with diabetes [1]. A role for immune cells such as monocytes and lymphocytes has been implicated in the pathogenesis of diabetes and its various complications including atherosclerosis. Clinical and experimental evidence indicates that inflammatory processes in the vascular wall are the decisive factor that accounts for the rate of lesion formation and clinical development in patients suffering from atherosclerosis [2]. Monocytes and macrophages, in an attempt to engulf lipid laden cells along the blood vessel, will get exposed to hyperglycemia and hyperlipidemia, a combined pathophysiological situation referred to as "glucolipotoxicity." The exact mechanisms by which glucolipotoxicity triggers monocyte activation and atherosclerotic processes are not clearly understood. However, evidence indicates that ER stress plays an important role in these mechanisms.

ER stress is known to activate a series of signals that comprise the unfolded protein response (UPR). The UPR includes at least three signaling pathways initiated by the kinases IRE1 and PERK and the transcription factor ATF6 [3] signals that coordinate the cellular response to unfolded proteins, which includes (a) downregulation of protein translation, (b) enhanced expression of ER chaperone proteins that promote protein refolding, and (c) activation of proteases involved in the degradation of misfolded proteins. 
Conversely, prolonged or severe ER stress can lead to the activation of apoptotic cell death. Recent studies have suggested that chronic ER stress originating from glucolipotoxicity is one of the major culprits that can very well explain the underlying causes of both insulin resistance and $\beta$-cell dysfunction [4-7]. ER stress has been linked to insulin resistance in diabetes and also expansion of ER was detected in $\beta$-cells from type 2 diabetic patients $[8,9]$. Furthermore, increased expression of ER stress markers has been demonstrated in $\mathrm{db} / \mathrm{db}$ mouse islets and $\beta$-cells of type 2 diabetes patients $[9,10]$. Recent studies also imply that $\beta$-cell dysfunction by glucolipotoxicity-induced ER stress is mediated by increased oxidative stress and apoptosis [11]. While the recruitment of monocytes and their retention within atherosclerotic lesions contribute to plaque development [12], macrophage apoptosis within advanced atherosclerotic lesions is also known to increase the risk of atherothrombotic disease [13]. Although glucolipotoxicity is known to trigger ER stress, its effect on various arms of the ER stress machinery in monocytes has not been clearly defined. Therefore, we investigated the effect of glucolipotoxicity on monocytes with reference to ROS generation, transcriptional alterations of various ER stress markers, and apoptotic indicators. We also investigated the effect of 4-phenyl butyric acid (PBA, a chemical chaperone) whether it resists glucolipotoxicityinduced ER stress and apoptosis.

\section{Materials and Methods}

2.1. Cell Culture and Treatment. The human monocyte THP1 cells were obtained from the National Centre for Cell Science (NCCS, Pune, India). THP-1 cells were maintained in endotoxin-free RPMI-1640 containing $5.5 \mathrm{mM}$ glucose, $10 \%(\mathrm{v} / \mathrm{v})$ heat-inactivated fetal bovine serum, $100 \mathrm{U} / \mathrm{mL}$ penicillin, $100 \mu \mathrm{g} / \mathrm{mL}$ streptomycin, $2.5 \mu \mathrm{g} / \mathrm{L}$ amphotericin B, $2 \mathrm{mM}$ L-glutamine, $1 \mathrm{mM}$ sodium pyruvate and $10 \mathrm{mM}$ HEPES, pH 7.0-7.4, under a humidified condition of 5\% $\mathrm{CO}_{2}$ at $37^{\circ} \mathrm{C}$. For all the experiments, cells were subjected to either $5.5 \mathrm{mM}$ glucose (basal) or glucolipotoxicity $(25 \mathrm{mM}$ glucose plus $0.5 \mathrm{mM}$ palmitic acid) or tunicamycin $(4 \mu \mathrm{M})$ treatment for $24 \mathrm{~h}$ in the presence and absence of 4 PBA $(1 \mathrm{mM})$, in serum-free medium. All experiments were independently performed at least thrice.

2.2. Intracellular Reactive Oxygen Species (ROS) Measurement. Intracellular ROS generation was measured in THP1 monocytes as described earlier [14] with minor modifications as to the confocal application. Briefly, $1 \times 10^{3}$ cells were seeded in confocal chambered slides (LabTek II) precoated with $0.01 \%$ poly-L-lysine. After the treatment conditions, $2^{\prime}, 7^{\prime}$-dichlorodihydrofluorescein diacetate $(\mathrm{H} 2$ DCFDA, $10 \mu \mathrm{M})$ dye was added to each well and incubated for $30 \mathrm{~min}$ at $37^{\circ} \mathrm{C}$. Cells were then washed twice with PBS. To capture the change in fluorescence, cells were excited at a wavelength of $485 \mathrm{~nm}$ and the fluorescence emission was read at $530 \mathrm{~nm}$ using Carl Zeiss-LSM 700 confocal microscope with an objective of 20x. Change in mean fluorescence intensity was represented as arbitrary units (AU).

\subsection{Real-Time PCR}

2.3.1. RNA Isolation. Total RNA from cells was isolated as described previously [15]. The RNA quality and concentration of total RNA were measured using nanodrop. $1 \mu \mathrm{g}$ of RNA was converted to cDNA using 100 units reverse transcriptase enzyme, $40 \mu \mathrm{M}$ Oligo-dT18 primer (New England Biolabs), 10xRT buffer, 20 U RNase inhibitor (Amersham Biosciences), and $2.5 \mathrm{mM}$ each of dNTPS and incubated at $42^{\circ} \mathrm{C}$ for $1 \mathrm{~h}$.

2.3.2. Quantitative Real-Time PCR. Quantitative real-time PCR was performed for specific genes using SYBR green master mix (Finnzymes). PCR amplification was carried out using ABI-7000 (Applied Biosystems) with cycle conditions (initial cycle: $50^{\circ} \mathrm{C}$ for $2 \mathrm{~min}$, Initial denaturation $95^{\circ} \mathrm{C}$ for $15 \mathrm{sec}, 40$ cycles of denaturation $95^{\circ} \mathrm{C}$ for $15 \mathrm{sec}$, and annealing/extension of $60^{\circ} \mathrm{C}$ for $1 \mathrm{~min}$ ). The expression level of RNA was determined using $2^{-D D C t}$ and normalized using $\beta$-actin. The primer sequences of specific genes are listed in Table 1.

2.4. Protein Expression. After specific treatments, cells were lysed using RIPA buffer (50 mM Tris- $\mathrm{HCl}$ (pH 8.0), $150 \mathrm{mM}$ $\mathrm{NaCl}, 0.1 \%$ SDS, $0.2 \%$ sodium azide, $1 \%$ Triton X-100, $0.25 \%$ sodium deoxycholate, and $1 \mathrm{x}$ protease inhibitor). In brief, cells were sonicated and incubated for $1 \mathrm{hr}$ in ice and centrifuged at $16,000 \mathrm{~g}$ for 5 minutes at $4^{\circ} \mathrm{C}$. The supernatant collected was quantified for protein by Bradford method. $15 \mu \mathrm{g}$ protein was resolved on a $10 \%$ SDS-PAGE and transferred to polyvinylidine fluoride (PVDF) membrane. After 1 hour blocking in $5 \%$ bovine serum albumin (BSA) and incubation with the appropriate primary antibodies and HRPconjugated secondary antibodies, detection was performed using enhanced chemiluminescence kit (GE Healthcare). $\beta$ actin was used as internal control. Mean densitometry data from independent experiments were normalized to control using Image-J software and represented as the ratio of test protein and $\beta$-actin.

2.5. DNA Damage-Comet Assay. DNA damage was evaluated with the Comet assay as described previously [16]. Briefly, the treated cells were mixed with $200 \mu \mathrm{L}$ of $0.5 \%$ low-melting point agarose and layered over clear microscope slides precoated with $1 \%$ normal melting agarose. Lysis, electrophoresis, and neutralization were followed by staining with ethidium bromide. The slides were examined under a fluorescent microscope. They were scored using an image analysis system (Comet Imager 1.2.13) attached to a fluorescent microscope (Carl-Zeiss, Germany) equipped with appropriate filter.

2.6. Caspase 3 Activity Assay. Caspase-3 activity was determined by colorimetric assay using the caspase-specific peptide containing amino acid sequence Asp-Glu-Val-Asp (DEVD) that is conjugated to the color reporter molecule p-nitroanilide (pNA) (RandD systems). The cleavage of the peptide by the caspases releases the chromophore pNA, 
TABle 1: Primer sequence of specific genes.

\begin{tabular}{ll}
\hline \multirow{2}{*}{ GRP78 } & $\begin{array}{l}\text { Forward CTG CCA TGG TTC TCA CTA AAA TG } \\
\text { Reverse TTA GGC CAG CAA TAG TTC CAG }\end{array}$ \\
\hline \multirow{2}{*}{ PERK } & $\begin{array}{l}\text { Forward GAA CCA GAC GAT GAG ACA GAG } \\
\text { Reverse GGA TGA CAC CAA GGA ACC G }\end{array}$ \\
\hline \multirow{2}{*}{ IRE1 } & Forward GCG AAC AGA ATA CAC CAT CAC \\
& Reverse ACC AGC CCA TCA CCA TTG \\
\hline \multirow{2}{*}{ XBP1 } & Forward TGG ATT CTG GCG GTA TTG AC \\
& Reverse TCC TTC TGG GTA GAC CTCTG \\
ATF-6 & $\begin{array}{l}\text { Forward CCT GTC CTA CAA AGT ACC ATG AG } \\
\text { Reverse CCT TTA ATC TCG CCT CTA ACC C }\end{array}$ \\
\hline \multirow{2}{*}{ CHOP/GADD } & Forward GTA CCT ATG TTT CAC CTC CTG G \\
& Reverse TGG AAT CTG GAG AGT GAG GG \\
\hline \multirow{2}{*}{ TRPC6 } & Forward TTT GAG GAG GGC AGA ACA CTT \\
& CCT \\
\hline \multirow{2}{*}{-actin } & Feverse TAT GGC CCT GGA ACA GCT CAG AAA \\
\hline
\end{tabular}

which is quantified spectrophotometrically at $405 \mathrm{~nm}$. Cells harvested after treatment were lysed and $10 \mu \mathrm{g}$ protein was aliquoted from each sample into a 96 well plate. $0.5 \mu \mathrm{L}$ DTT was added to all the wells followed by addition of $50 \mu \mathrm{L}$ of $2 \mathrm{x}$ reaction buffer and $3.5 \mu \mathrm{L}$ of Caspase- 3 colorimetric substrate. The plate was incubated at $37^{\circ} \mathrm{C}$ for $1 \mathrm{hr}$ and read at $405 \mathrm{~nm}$ using microplate reader. Caspase-3 activity was expressed as mean \pm SEM of optical density.

2.7. Statistical Analysis. Statistical Package for Social Sciences (SPSS) Windows, (Version 16.0, Chicago, IL), was used for statistical analysis. Data were expressed as Mean \pm SEM. Comparisons between groups were performed using student's $t$-test and a $P$-value $<0.05$ was considered statistically significant.

\section{Results}

We have applied confocal microscopy to measure the fluorescent intensity of DCF which indicates the extent of intracellular ROS generation in monocytes. While representative fluorescent images related to ROS generation were depicted in Figure 1(a), cumulative data on ROS generation were presented in Figure 1(b). Cells subjected to either glucolipotoxicity or tunicamycin exhibited increased ROS generation compared to the untreated cells (Figure 1(b)). Pretreatment of cells with 4-phenyl butyric acid showed significant reduction in $\operatorname{ROS}$ generation $(P<0.05)$. A complete mRNA expression pattern of ER stress machinery was determined by real-time PCR and the cumulative data on mRNA pattern of ER stress markers in relation to their ratio with the house keeping $\beta$-actin was depicted in Figure 2. Compared to untreated cells, cells treated with glucolipotoxicity or tunicamycin showed an increased mRNA expression of PERK, GRP78, IRE1 $\alpha$, XBP1, ATF6, and CHOP (Figures $2(a)-2(f))$. It is also interesting to note that the extent increase in ER stress markers under glucolipotoxicity was higher than that induced by tunicamycin. PBA treatment significantly reduced all the transcriptional expression of ER stress markers most likely due to its chaperone activity. Figure 3(A) depicts the representative protein expression of ER stress markers along with $\beta$-actin. Consistent with the mRNA results, protein expression of ER stress markers, namely, PERK, GRP78, IRE1 $\alpha$, and XBP1 were also increased in cells subjected to glucolipotoxicity and tunicamycin treatment (Figure 3(B)). 4-PBA treatment significantly reduced the protein expression of all the ER stress markers.

Since the programming of apoptosis by both the oxidative and ER stress signals depend on the load of intracellular $\mathrm{Ca}^{2+}$, we investigated the transcriptional level of TRPC6 , which is an important driving force for increased $\mathrm{Ca}^{2+}$ influx. Cells treated with glucolipotoxicity or tunicamycin resulted in several folds of increase in TRPC- 6 mRNA levels (Figure 4) and this was significantly normalized by PBA.

Compared to untreated cells, cells treated with glucolipotoxicity or tunicamycin showed increased DNA damage (4.6 and 3 folds, resp.). Interestingly, PBA treatment significantly reduced the DNA damage induced either by glucolipotoxicity or tunicamycin (Figure 5(a)). Since CHOP (an intermediate in caspase-dependent apoptosis) mRNA and protein expression were increased in cells subjected to glucolipotoxicity or tunicamycin, we estimated the activity of caspase- 3 enzyme. As expected, cells treated with glucolipotoxicity or tunicamycin showed significantly increased caspase-3 activity (Figure 5(b)) implying that uncontrolled ER stress might have programmed the cells towards apoptosis. Increased caspase-3 activity either due to glucolipotoxicity or tunicamycin was significantly $(P<0.05)$ reduced by 4 -PBA.

\section{Discussion}

The following are the nutshell findings of the study. First, monocytes subjected to glucolipotoxicity showed increased ROS generation and increased mRNA expression of several genes of the ER stress machinery. Secondly, these monocytes exhibited features of chronic ER stress as evidenced by increased mRNA expression of TRPC-6, DNA damage, and caspase-3 activity. Thirdly, PBA-a chemical chaperone, resisted all the glucolipotoxicity-induced cellular and molecular alterations in monocytes emphasizing the benefits of ER stress alleviation.

Monocyte activation, adhesion to the endothelium, and transmigration into the subendothelial space are key events in early pathogenesis of atherosclerosis. The mechanisms by which glucose and lipid toxicity induces monocyte-associated atherosclerosis are only partially known. Mononuclear blood cells from patients with diabetes show increased generation of reactive oxygen species and altered redox signaling [16-21]. In our study, monocytes subjected to glucolipotoxicity exhibited increased generation of ROS. ROS could activate cell death processes directly by the oxidation of proteins, lipids, and/or nucleic acids or could act as initiators or second messengers in the cell 

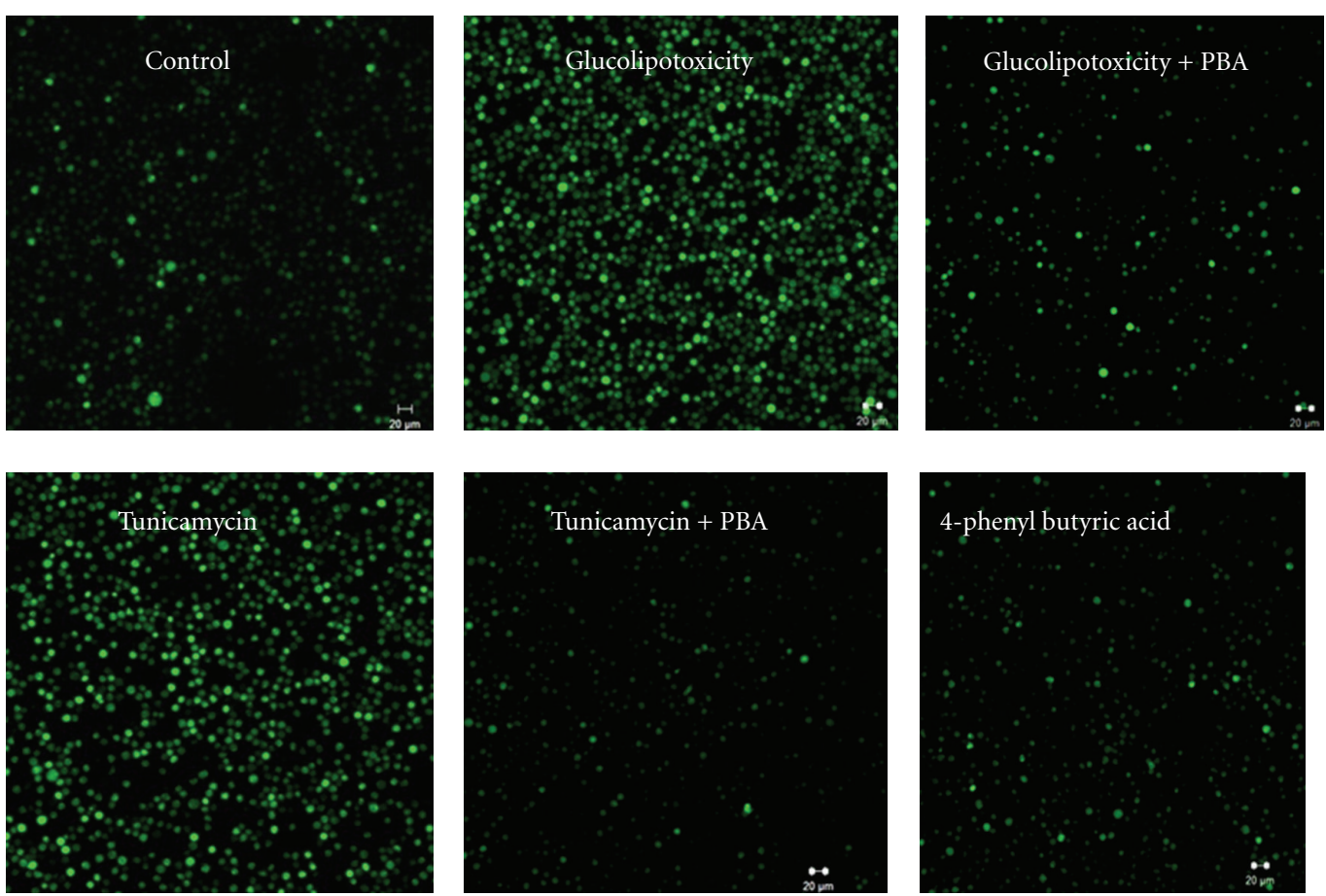

(a)

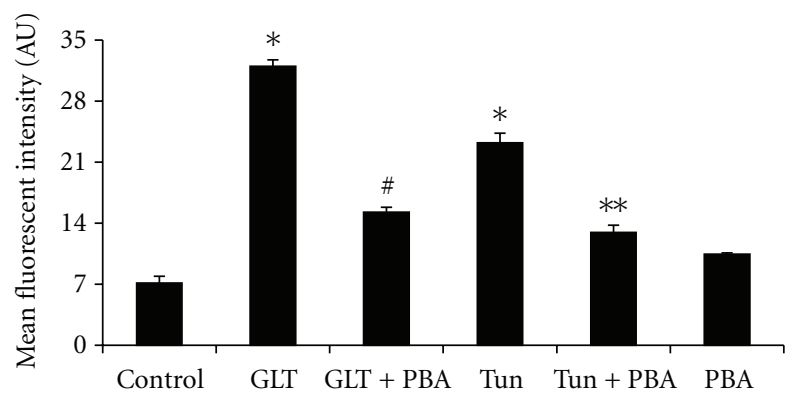

(b)

FIGURE 1: (a) Representative confocal microscopy images of Intracellular ROS generation in cells treated under various conditions. (b) Mean $( \pm$ SEM) fluorescence intensities of ROS under different experimental maneuvers, namely, control, glucolipotoxicity (GLT), glucolipotoxicity + 4-phenyl butyric acid (GLT + PBA), tunicamycin (Tun), tunicamycin + 4-phenyl butyric acid (Tun + PBA), 4-phenyl butyric acid (PBA). ${ }^{*} P<0.05$ compared to control, ${ }^{\#} P<0.05$ compared to GLT, ${ }^{*} P<0.05$ compared to tunicamycin.

death process. Accumulating evidence suggests that protein folding and generation of reactive oxygen species (ROS) as a byproduct of protein oxidation in the ER are closely linked events. It has also become apparent that activation of the UPR on exposure to oxidative stress is an adaptive mechanism to preserve cell function and survival. However, persistent oxidative stress and protein misfolding initiate apoptotic cascades and are now known to play predominant roles in the pathogenesis of multiple human diseases including diabetes and atherosclerosis [22-24].

A number of hypotheses have been conceived to explain advanced lesional macrophage apoptosis and atherosclerosis, and undoubtedly more than one mechanism is involved. Recent mechanistic data in cultured cells and correlative and genetic causation evidence in vivo support a role for endoplasmic reticulum (ER) stress in advanced lesional macrophage apoptosis and its major consequence of plaque necrosis $[13,25]$. Consistent with previous findings, glucolipotoxicity in our study showed increased transcription of PERK, GRP78, IRE1 $\alpha$, XBP-1, ATF6, and CHOP in monocytes. This was also corroborated by the increased protein expression of ER stress markers. The fact that increased expression of ER stress markers under glucolipotoxicity is similar to that induced by tunicamycin (a known inducer of ER stress) emphasizes that glucolipotoxicity inducts ER stress in monocytes.

Increased TRPC-6 mRNA expression under glucolipotoxicity in our study implies a role for increased calcium levels in monocyte dysfunction and ER stress. Calcium is an essential intracellular messenger and serves critical cellular functions in both excitable and nonexcitable cells. Available data on transient receptor potential conical (TRPC) protein 


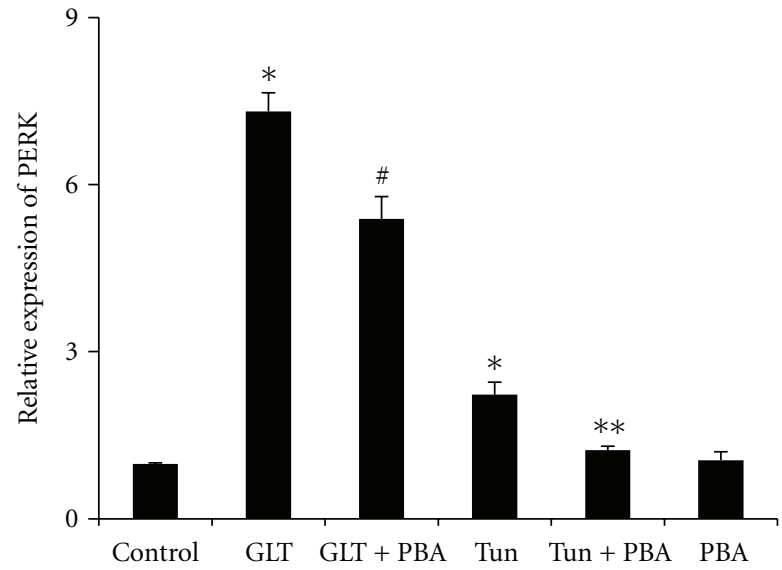

(a) PERK

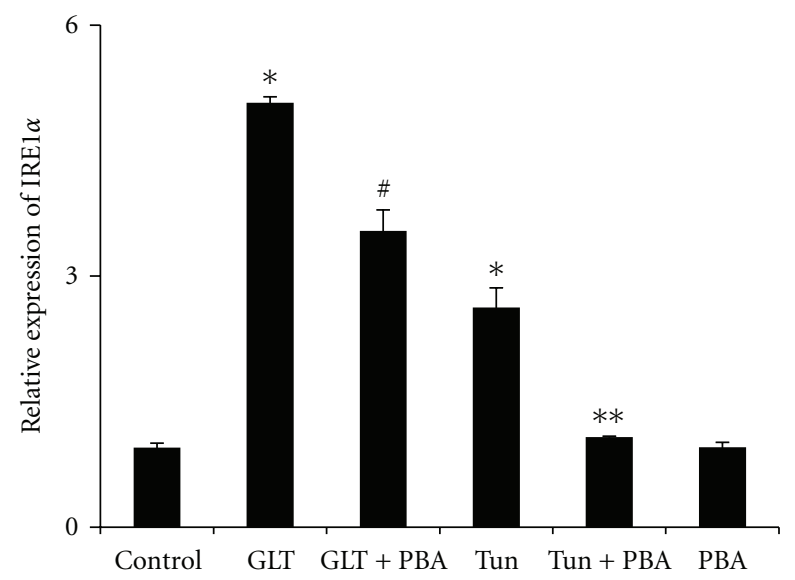

(c) IRE1 $\alpha$

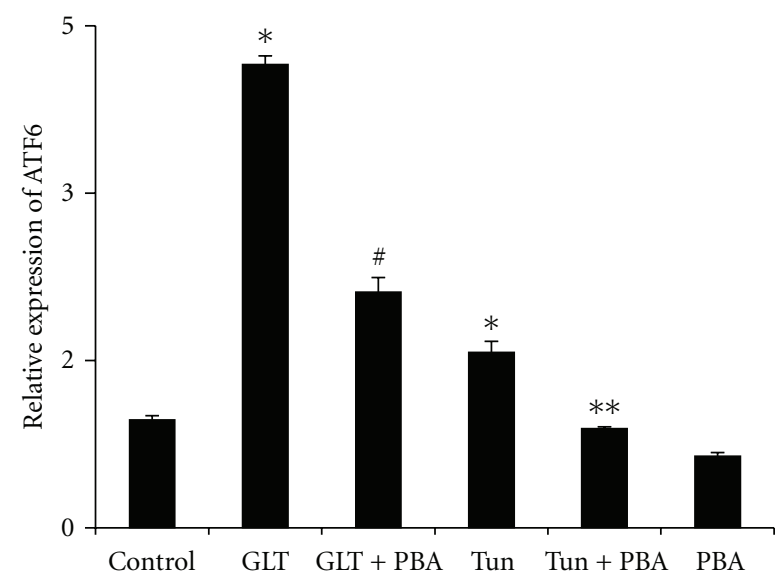

(e) ATF6

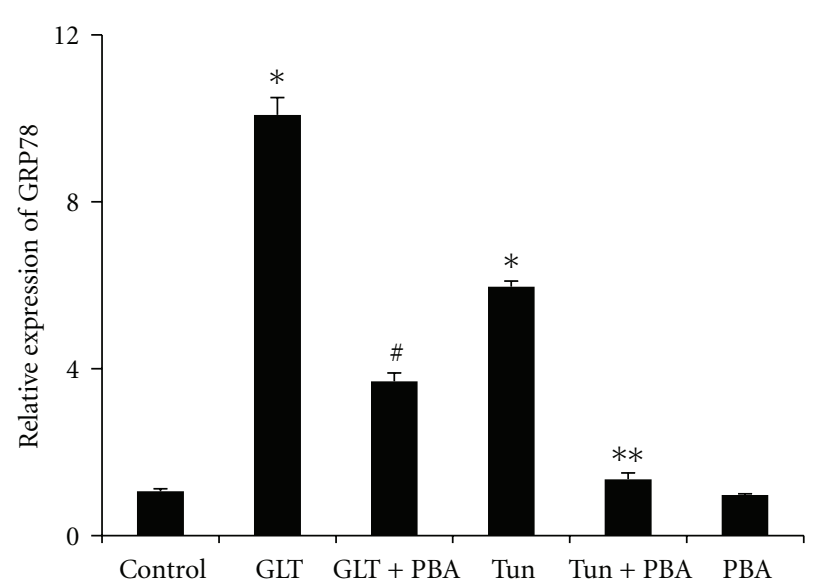

(b) GRP78

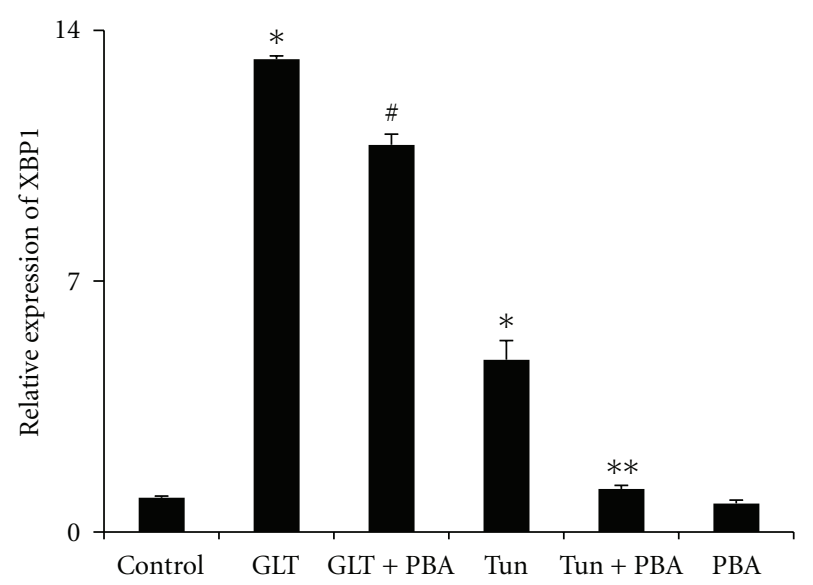

(d) XBP-1

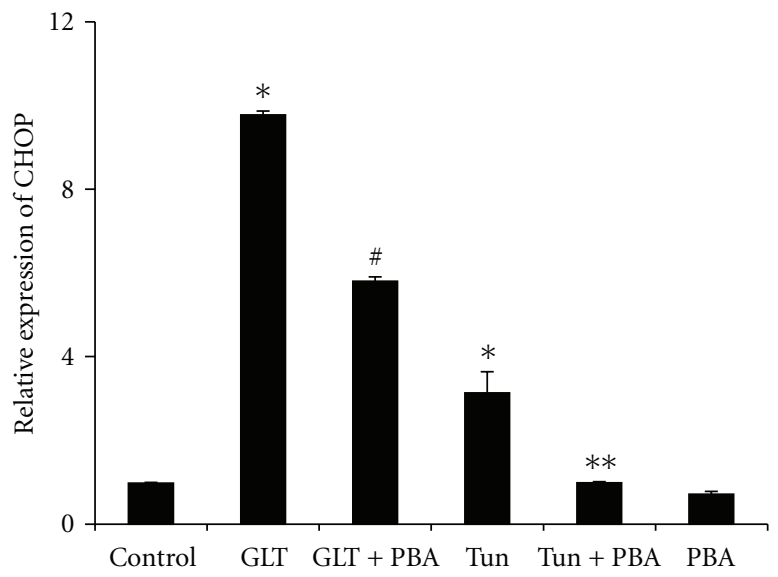

(f) $\mathrm{CHOP}$

FIGURE 2: Relative gene expression Mean ( \pm SEM) data of ER stress markers namely, PERK (a), GRP78 (b), IRE1 $\alpha$ (c), XBP-1 (d), ATF6 (e), CHOP (f). ${ }^{*} P<0.05$ compared to control, ${ }^{*} P<0.05$ compared to GLT, ${ }^{* *} P<0.05$ compared to tunicamycin.

indicate that these proteins initiate $\mathrm{Ca}^{2+}$ entry pathways and are essential in maintaining cytosolic, ER, and mitochondrial $\mathrm{Ca}^{2+}$ levels [26]. Alterations in $\mathrm{Ca}^{2+}$ homeostasis have been suggested in diabetes and associated complications $[27,28]$. Zhu et al. [28] have recently reviewed a role for TRP channels and their implications in metabolic diseases. Activity of
TRPC is physiologically important as $\mathrm{Ca}^{2+}$ concentrations within the ER must be maintained at sufficient levels in order for the organelle to carry out many of its fundamental functions including protein folding and trafficking. However, loss of $\mathrm{Ca}^{2+}$ homeostasis due to improper TRPC activation could lead to ER stress responses, and even apoptosis [29]. While 


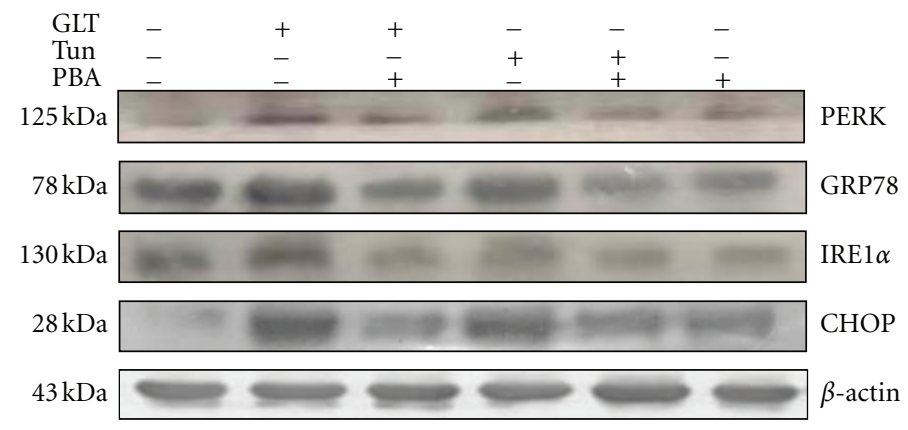

(A)

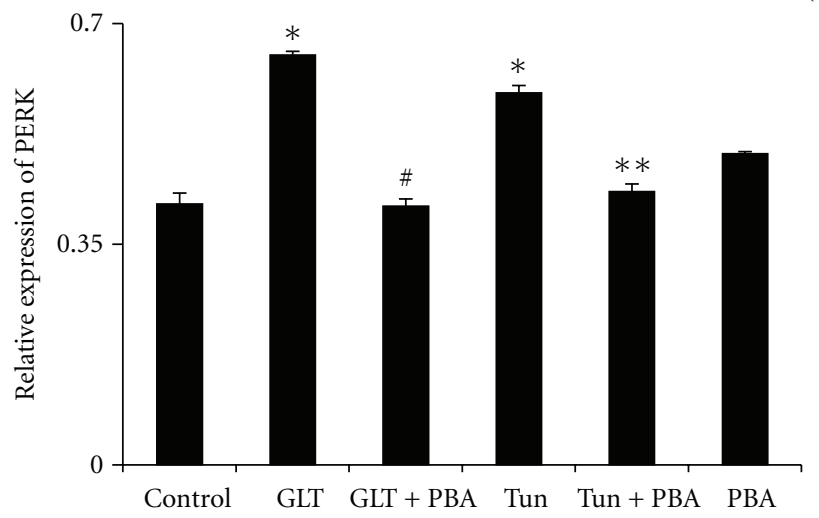

(a) PERK

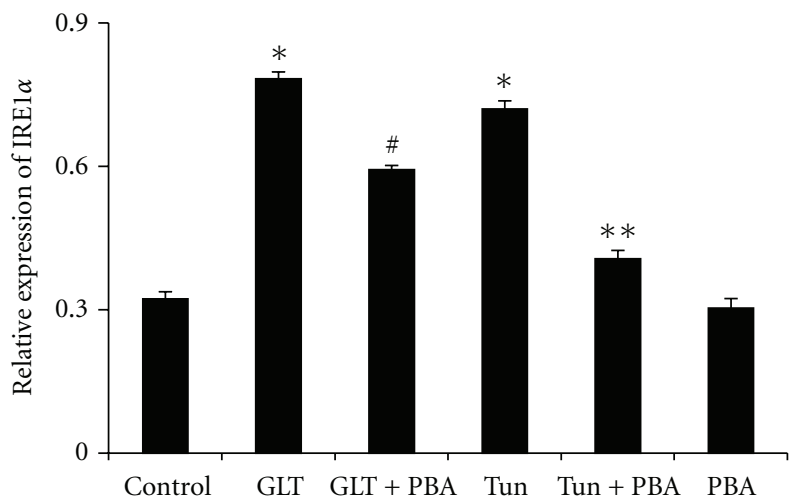

(c) IRE1 $\alpha$

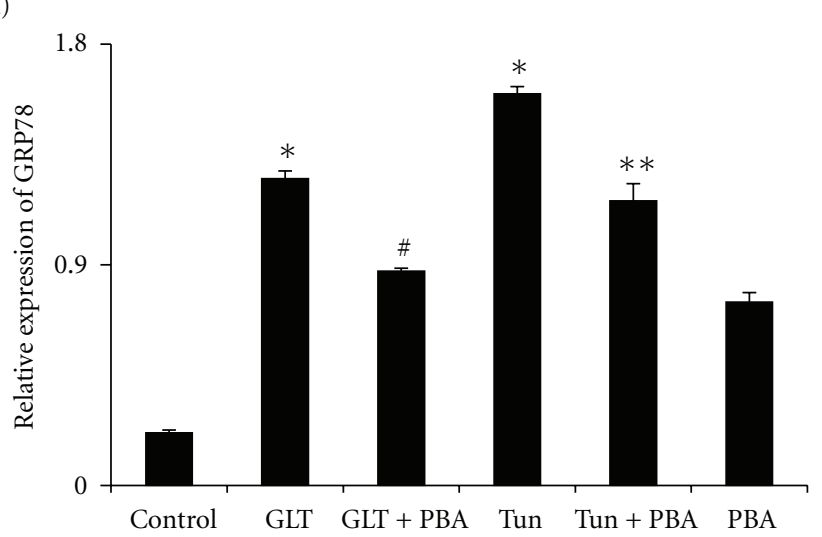

(b) GRP-78

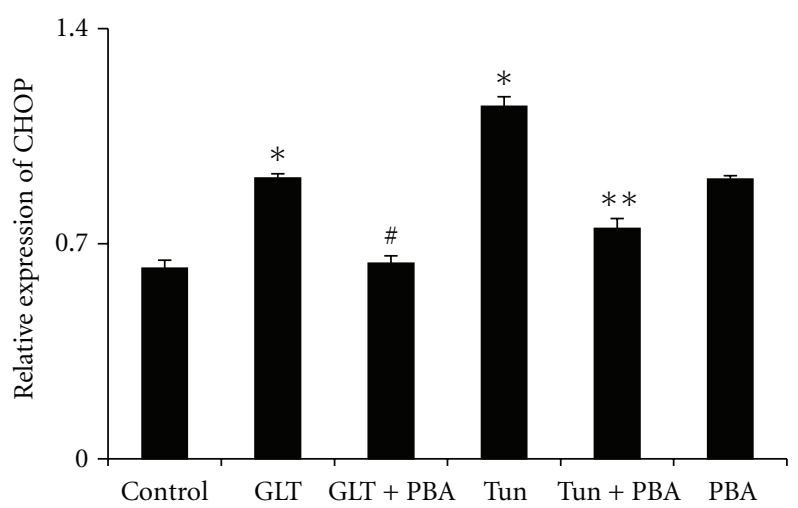

(d) $\mathrm{CHOP}$

(B)

FIGURE 3: (A) Representative protein expression data on ER stress protein markers, namely, PERK (1), GRP78 (2), IRE1 $\alpha$ (3), and CHOP (4). (B) Cumulative histogram data Mean $\left( \pm\right.$ SEM) of ER stress markers, namely, PERK (a), GRP78 (b), IRE1 $\alpha$ (c) and CHOP (d). ${ }^{*} P<0.05$ compared to control, ${ }^{\#} P<0.05$ compared to GLT, ${ }^{* *} P<0.05$ compared to tunicamycin.

oxidative stress could result in cellular defects including a defect in $\mathrm{ER} \mathrm{Ca}^{2+}$ uptake and $\mathrm{Ca}^{2+}$ efflux, thereby increasing $\left[\mathrm{Ca}^{2+}\right]_{\mathrm{i}}$ and $\mathrm{Ca}^{2+}$ influx [30], several TRPC families have also been shown directly activated in response to oxidative stress [31]. In our study, both glucolipotoxicity and tunicamycin resulted in increased ROS generation in monocytes and, at the transcription level, we have also witnessed the increased TRPC6 mRNA expression. Among the TRPC subfamily of TRP channels, TRPC6 is gated by signal transduction pathways that activate C-type phospholipases as well as by direct exposure to diacylglycerols [32]. Recent studies emphasize a pathophysiological role of TRPC6 in several disease states $[33,34]$ and it appears to be an emerging drug target. Altered TRPC6 regulation and impaired capacitative calcium entry have been shown in vessels of diabetic patients [35]. While a role for oxidative stress has been implicated in the pathogenesis of Type 2 diabetes and its micro- and macrovascular complications [20], TRPC6 mRNA was also 


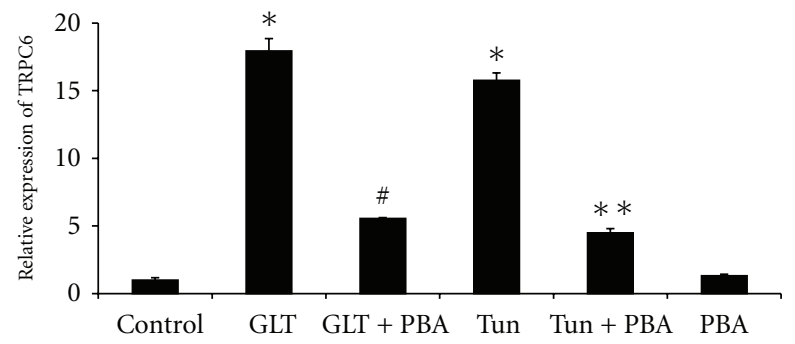

Figure 4: Mean $\left( \pm\right.$ SEM) mRNA expression of TRPC-6. ${ }^{*} P<0.05$ compared to control, ${ }^{\#} P<0.05$ compared to GLT, ${ }^{* *} P<0.05$ compared to tunicamycin.

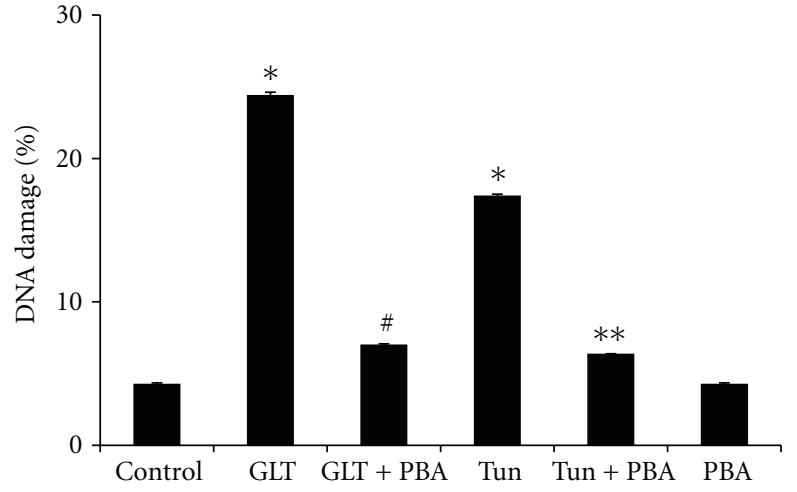

(a)

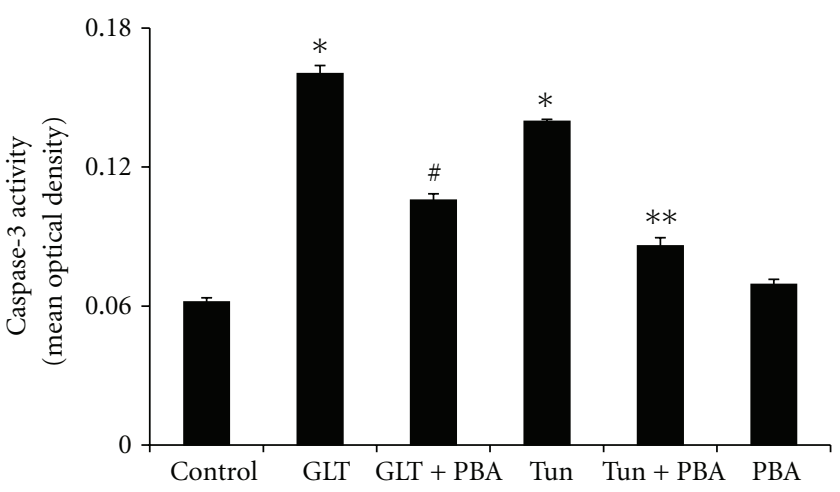

(b)

Figure 5: (a) Mean $\left( \pm\right.$ SEM) percentage DNA damage under different experimental conditions. ${ }^{*} P<0.05$ compared to control, ${ }^{\#} P<0.05$ compared to GLT, ${ }^{* *} P<0.05$ compared to tunicamycin. (b) Mean $( \pm$ SEM) Caspase 3 activity under different experimental conditions. ${ }^{*} P<0.05$ compared to control, ${ }^{\#} P<0.05$ compared to GLT, ${ }^{*} P<0.05$ compared to tunicamycin.

shown significantly higher in monocytes from patients with type 2 diabetes [36] pointing to a novel pathway for increased activation of monocytes and hence atherosclerosis in patients with diabetes.

ER stress is one of the damaging stresses resulting from glucolipotoxicity which can lead to apoptosis when the stress is prolonged or uncontrolled. Komura et al. [37] have shown that monocytes of diabetic patients are not as efficient in phagocytosing as in normal healthy people and electron microscopic examination of monocytes revealed morphologic alterations in the ER of cells derived from patients with diabetes. Although it has been known that activation of the CHOP pathway of the UPR can cause apoptosis, the molecular mechanisms linking CHOP to death execution pathways is poorly understood. Our results here show that apoptosis might be executed by the increased activation of caspase-3 under glucolipotoxicity. Since autophagy has been proposed to operate as an alternative cell death mechanism or act upstream of apoptosis [38], it is plausible that glucolipotoxicity-induced ER stress could also promote cell death via autophagy [39, 40]. ER stress-induced UPR activation can also influence the expression of certain inflammatory cytokines [41] rendering the monocyte intrinsically proinflammatory which might have drastic consequences when monocytes infiltrate the intima of the vessel wall. Recent work has provided evidence for a calcium dependent mechanism in ER stress-induced macrophage apoptosis [42]. The increased mRNA levels of TRPC- 6 seen in our study also support this. Since caspase and the downstream apoptosis effector molecules are $\mathrm{Ca}^{2+}$-dependent, future studies should also focus on the involvement of intracellular calcium in the induction of apoptosis in ER-stressed cells under glucose and lipid dyshomeostasis.

In our study, glucolipotoxicity-induced ROS generation and increased ER stress markers seen under glucolipotoxicity were normalized by PBA. Drugs that interfere with ER stress have wide therapeutic potential and recently chemical chaperones like tauroursodeoxycholic acid (TUDCA), and PBA received much attention because of their ER stress alleviating activities as these compounds improve ER folding capacity and help in stabilizing protein conformation [43]. PBA was found to be protective in in vitro and in vivo models of diabetes [43-45]. Accumulating evidence suggests that protein folding and generation of reactive oxygen species (ROS) as a byproduct of protein oxidation in the ER are closely linked events. While facilitating appropriate protein folding, PBA helps maintaining the balance between ER oxidoreductin 1 (ERO1) and protein disulfide isomerase (PDI) and thereby reduces the ROS levels generated during protein oxidation [46]. It has also been shown that PBA counteracts oxidative stress by upregulating the expression and activity of superoxide dismutase (SOD) $[47,48]$. Luo 
et al. [49] have also demonstrated PBA inhibition of NADPH oxidase activity and emphasized a dual regulation ER stress and oxidative stress by PBA. Erbay et al. [50] demonstrated that mitigation of ER stress with PBA protected macrophages against lipotoxic death and atherosclerosis by suppression of XBP1 splicing and CHOP expression. PBA has been shown to regulate ER stress and offer potential therapeutic benefits in several preclinical models of human diseases including type 2 diabetes [43, 51-55]. As an orally bioavailable terminal aromatic substituted fatty acid, PBA has been used for the treatment of urea cycle disorders [56]. More importantly, oral treatment of PBA was recently shown preventing lipidinduced impairment in insulin sensitivity and b-cell function in humans [57].

To conclude, our study exposes the convergence of ER stress, oxidative stress and apoptosis in the presence of glucolipotoxicity in monocytes and points out ER stress network as a novel drug-targetable pathway. Our results also emphasize that chemical chaperones enhance the adaptive capacity of the ER, and on further evaluation in appropriate clinical trials, could serve as potent antidiabetic/antiatherosclerotic modalities with potential application in the treatment of type 2 diabetes and its vascular complications like atherosclerosis.

\section{Abbreviations}

GRP-78: Glucose regulated protein-78

PERK: PKR like ER kinase

IRE-1 $\alpha$ : Inositol Requiring enzyme- $1 \alpha$

XBP-1: X box binding Protein

ATF-6: Activating transcription factor-6

CHOP: CCAAT/enhancer-binding Homologous

protein

GADD: Growth arrest and DNA damage protein

TRPC-6: Transient receptor protein channel-6.

\section{Acknowledgments}

This work was supported by the grants from the Department of Biotechnology (DBT), and the Department of Science and Technology (DST-Indo-Korea Project), New Delhi. Senior Research Fellowship (SRF) from the Council for Scientific and Industrial Research (CSIR), Delhi, is also thankfully acknowledged.

\section{References}

[1] K. T. Khaw, N. Wareham, S. Bingham, R. Luben, A. Welch, and N. Day, "Association of hemoglobin A1c with cardiovascular disease and mortality in adults: the European prospective investigation into cancer in Norfolk," Annals of Internal Medicine, vol. 141, no. 6, pp. 413-420, 2004.

[2] C. J. Binder, M. K. Chang, P. X. Shaw et al., "Innate and acquired immunity in atherogenesis," Nature Medicine, vol. 8, no. 11, pp. 1218-1226, 2002.

[3] D. Ron and P. Walter, "Signal integration in the endoplasmic reticulum unfolded protein response," Nature Reviews Molecular Cell Biology, vol. 8, no. 7, pp. 519-529, 2007.
[4] D. L. Eizirik, A. K. Cardozo, and M. Cnop, "The role for endoplasmic reticulum stress in diabetes mellitus," Endocrine Reviews, vol. 29, no. 1, pp. 42-61, 2008.

[5] V. Poitout and R. P. Robertson, "Glucolipotoxicity: fuel excess and $\beta$-cell dysfunction," Endocrine Reviews, vol. 29, no. 3, pp. 351-366, 2008.

[6] E. Bachar, Y. Ariav, M. Ketzinel-Gilad, E. Cerasi, N. Kaiser, and G. Leibowitz, "Glucose amplifies fatty acid-induced endoplasmic reticulum stress in pancreatic $\beta$-cells via activation of mTORC1," PLoS One, vol. 4, no. 3, Article ID e4954, 2009.

[7] M. Shimoda, Y. Kanda, S. Hamamoto et al., "The human glucagon-like peptide-1 analogue liraglutide preserves pancreatic beta cells via regulation of cell kinetics and suppression of oxidative and endoplasmic reticulum stress in a mouse model of diabetes," Diabetologia, vol. 54, no. 5, pp. 1098-1108, 2011.

[8] Y. Nakatani, H. Kaneto, D. Kawamori et al., "Involvement of endoplasmic reticulum stress in insulin resistance and diabetes," Journal of Biological Chemistry, vol. 280, no. 1, pp. 847-851, 2005.

[9] P. Marchetti, M. Bugliani, R. Lupi et al., "The endoplasmic reticulum in pancreatic beta cells of type 2 diabetes patients," Diabetologia, vol. 50, no. 12, pp. 2486-2494, 2007.

[10] D. R. Laybutt, A. M. Preston, M. C. Åkerfeldt et al., "Endoplasmic reticulum stress contributes to beta cell apoptosis in type 2 diabetes," Diabetologia, vol. 50, no. 4, pp. 752-763, 2007.

[11] K. Chen, P. Jin, H.-H. He, Y.-H. Xie, X.-Y. Xie, and Z.H. Mo, "Overexpression of Insig-1 protects $\beta$ cell against glucolipotoxicity via SREBP-1c," Journal of Biomedical Science, vol. 18, no. 1, article 57, 2011.

[12] J. Llodrá, V. Angeli, J. Liu, E. Trogan, E. A. Fisher, and G. J. Rendolph, "Emigration of monocyte-derived cells from atherosclerotic lesions characterizes regressive, but not progressive, plaques," Proceedings of the National Academy of Sciences of the United States of America, vol. 101, no. 32, pp. 11779-11784, 2004.

[13] E. Thorp, G. Li, T. A. Seimon, G. Kuriakose, D. Ron, and I. Tabas, "Reduced apoptosis and plaque necrosis in advanced atherosclerotic lesions of Apoe-/- and Ldlr-/ - mice lacking CHOP," Cell Metabolism, vol. 9, no. 5, pp. 474-481, 2009.

[14] M. Balasubramanyam, A. A. Koteswari, R. S. Kumar, S. F. Monickaraj, J. U. Maheswari, and V. Mohan, "Curcumininduced inhibition of cellular reactive oxygen species generation: novel therapeutic implications," Journal of Biosciences, vol. 28, no. 6, pp. 715-721, 2003.

[15] M. Balasubramanyam, S. Aravind, K. Gokulakrishnan et al., "Impaired miR-146a expression links subclinical inflammation and insulin resistance in Type 2 diabetes," Molecular and Cellular Biochemistry, vol. 351, no. 1-2, pp. 197-205, 2011.

[16] A. Adaikalakoteswari, M. Rema, V. Mohan, and M. Balasubramanyam, "Oxidative DNA damage and augmentation of poly(ADP-ribose) polymerase/nuclear factor-kappa B signaling in patients with Type 2 diabetes and microangiopathy," International Journal of Biochemistry and Cell Biology, vol. 39, no. 9, pp. 1673-1684, 2007.

[17] K. Hiramatsu and S. Arimori, "Increased superoxide production by mononuclear cells of patients with hypertriglyceridemia and diabetes," Diabetes, vol. 37, no. 6, pp. 832-837, 1988.

[18] N. N. Orie, W. Zidek, and M. Tepel, "Increased intracellular generation of reactive oxygen species in mononuclear leukocytes from patients with diabetes mellitus type 2," Experimental and Clinical Endocrinology and Diabetes, vol. 108, no. 3, pp. 175-180, 2000.

[19] R. Sampathkumar, M. Balasubramanyam, C. Tara, M. Rema, and V. Mohan, "Association of hypoglutathionemia with 
reduced $\mathrm{Na}^{+} / \mathrm{K}^{+}$ATPase activity in type 2 diabetes and microangiopathy," Molecular and Cellular Biochemistry, vol. 282, no. 1-2, pp. 169-176, 2006.

[20] M. Balasubramanyam, A. Adaikalakoteswari, R. Sampathkumar, and V. Mohan, "Oxidative stress in Asian Indians with Type 2 diabetes," in Type 2 diabetes in South Asians: Epidemiology, Risk Factors and Prevention, pp. 164-172, Jaypee Brothers, Medical Publishers, New Delhi, India, 2006.

[21] A. Adaikalakoteswari, M. Balasubramanyam, M. Rema, and V. Mohan, "Differential gene expression of NADPH oxidase (p22phox) and hemoxygenase-1 in patients with Type 2 diabetes and microangiopathy," Diabetic Medicine, vol. 23, no. 6, pp. 666-674, 2006.

[22] J. D. Malhotra and R. J. Kaufman, "Endoplasmic reticulum stress and oxidative stress: a vicious cycle or a double-edged sword?" Antioxidants and Redox Signaling, vol. 9, no. 12, pp. 2277-2293, 2007.

[23] M. Balasubramanyam, R. Lenin, and F. Monickaraj, "Endoplasmic reticulum stress in diabetes: new insights of clinical relevance," Indian Journal of Clinical Biochemistry, vol. 25, no. 2, pp. 111-118, 2010.

[24] V. Srinivasan, U. Tatu, V. Mohan, and M. Balasubramanyam, "Molecular convergence of hexosamine biosynthetic pathway and ER stress leading to insulin resistance in L6 skeletal muscle cells," Molecular and Cellular Biochemistry, vol. 328, no. 1-2, pp. 217-224, 2009.

[25] B. Feng, P. M. Yaol, Y. Li et al., "The endoplasmic reticulum is the site of cholesterol-induced cytotoxicity in macrophages," Nature Cell Biology, vol. 5, no. 9, pp. 781-792, 2003.

[26] G. M. Salido, S. O. Sage, and J. A. Rosado, "TRPC channels and store-operated $\mathrm{Ca}^{2+}$ entry," Biochimica et Biophysica Acta, vol. 1793, no. 2, pp. 223-230, 2009.

[27] M. Balasubramanyam, R. A. Balaji, B. Subashini, and V. Mohan, "Evidence for mechanistic alterations of $\mathrm{Ca}^{2+}$ homeostasis in Type 2 diabetes mellitus," International journal of experimental diabetes research, vol. 1, no. 4, pp. 275-287, 2001.

[28] Z. Zhu, Z. Luo, S. Ma, and D. Liu, "TRP channels and their implications in metabolic diseases," Pflugers Archiv European Journal of Physiology, vol. 461, no. 2, pp. 211-223, 2011.

[29] I. Yoshida, A. Monji, K. I. Tashiro, K. I. Nakamura, R. Inoue, and S. Kanba, "Depletion of intracellular $\mathrm{Ca}^{2+}$ store itself may be a major factor in thapsigargin-induced ER stress and apoptosis in PC12 cells," Neurochemistry International, vol. 48, no. 8, pp. 696-702, 2006.

[30] S. Orrenius, B. Zhivotovsky, and P. Nicotera, "Regulation of cell death: the calcium-apoptosis link," Nature Reviews Molecular Cell Biology, vol. 4, no. 7, pp. 552-565, 2003.

[31] B. A. Miller, "The role of TRP channels in oxidative stressinduced cell death," Journal of Membrane Biology, vol. 209, no. 1, pp. 31-41, 2006.

[32] A. Dietrich, M. Mederos Y Schnitzler, M. Gollasch et al., "Increased vascular smooth muscle contractility in $\mathrm{TRPC}^{6-/-}$ mice," Molecular and Cellular Biology, vol. 25, no. 16, pp. 6980-6989, 2005.

[33] N. Onohara, M. Nishida, R. Inoue et al., "TRPC3 and TRPC6 are essential for angiotensin II-induced cardiac hypertrophy," EMBO Journal, vol. 25, no. 22, pp. 5305-5316, 2006.

[34] S. Chen, F.-F. He, H. Wang et al., "Calcium entry via TRPC6 mediates albumin overload-induced endoplasmic reticulum stress and apoptosis in podocytes," Cell Calcium, vol. 50, no. 6, pp. 523-529, 2011.

[35] A. W. Y. Chung, K. Au Yeung, E. Chum, E. B. Okon, and C. van Breemen, "Diabetes modulates capacitative calcium entry and expression of transient receptor potential canonical channels in human saphenous vein," European Journal of Pharmacology, vol. 613, no. 1-3, pp. 114-118, 2009.

[36] T. Wuensch, F. Thilo, K. Krueger, A. Scholze, M. Ristow, and M. Tepel, "High glucose-induced oxidative stress increases transient receptor potential channel expression in human monocytes," Diabetes, vol. 59, no. 4, pp. 844-849, 2010.

[37] T. Komura, Y. Sakai, M. Honda, T. Takamura, K. Matsushima, and S. Kaneko, "CD14 monocytes are vulnerable and functionally impaired under endoplasmic reticulum stress in patients with type 2 diabetes," Diabetes, vol. 59, no. 3, pp. 634643, 2010.

[38] A. Eisenberg-Lerner, S. Bialik, H. U. Simon, and A. Kimchi, "Life and death partners: apoptosis, autophagy and the crosstalk between them," Cell Death and Differentiation, vol. 16, no. 7, pp. 966-975, 2009.

[39] C. D. Gonzalez, M. S. Lee, P. Marchetti et al., "The emerging role of autophagy in the pathophysiology of diabetes mellitus," Autophagy, vol. 7, no. 1, pp. 2-11, 2011.

[40] N. A. Kaniuk, M. Kiraly, H. Bates, M. Vranic, A. Volchuk, and J. H. Brumell, "Ubiquitinated-protein aggregates form in pancreatic $\beta$-cells during diabetes-induced oxidative stress and are regulated by autophagy," Diabetes, vol. 56, no. 4, pp. 930939, 2007.

[41] T. P. Carroll, C. M. Greene, C. A. O’Connor, A. M. Nolan, S. J. O’Neill, and N. G. McElvaney, "Evidence for unfolded protein response activation in monocytes from individuals with $\alpha-1$ antitrypsin deficiency," Journal of Immunology, vol. 184, no. 8, pp. 4538-4546, 2010.

[42] I. Tabas, "The role of endoplasmic reticulum stress in the progression of atherosclerosis," Circulation Research, vol. 107, no. 7, pp. 839-850, 2010.

[43] U. Özcan, E. Yilmaz, L. Özcan et al., "Chemical chaperones reduce ER stress and restore glucose homeostasis in a mouse model of type 2 diabetes," Science, vol. 313, no. 5790, pp. 11371140, 2006.

[44] S. E. Choi, Y. J. Lee, H. J. Jang et al., "A chemical chaperone 4-PBA ameliorates palmitate-induced inhibition of glucosestimulated insulin secretion (GSIS)," Archives of Biochemistry and Biophysics, vol. 475, no. 2, pp. 109-114, 2008.

[45] S. Basseri, Š. Lhoták, A. M. Sharma, and R. C. Austin, "The chemical chaperon 4-phenylbutyrate inhibits adipogenesis by modulating the unfolded protein response," Journal of Lipid Research, vol. 50, no. 12, pp. 2486-2501, 2009.

[46] F. E. Cohen and J. W. Kelly, "Therapeutic approaches to protein-misfolding diseases," Nature, vol. 426, no. 6968, pp. 905-909, 2003.

[47] C. Daosukho, Y. Chen, T. Noel et al., "Phenylbutyrate, a histone deacetylase inhibitor, protects against Adriamycininduced cardiac injury," Free Radical Biology and Medicine, vol. 42, no. 12, pp. 1818-1825, 2007.

[48] T. Adachi, H. Yasuda, S. Nakamura et al., "Endoplasmic reticulum stress induces retinal endothelial permeability of extracellular-superoxide dismutase," Free Radical Research, vol. 45, no. 9, pp. 1083-1092, 2011.

[49] Z. F. Luo, B. Feng, J. Mu et al., "Effects of 4-phenylbutyric acid on the process and development of diabetic nephropathy induced in rats by streptozotocin: regulation of endoplasmic reticulum stress-oxidative activation," Toxicology and Applied Pharmacology, vol. 246, no. 1-2, pp. 49-57, 2010.

[50] E. Erbay, V. R. Babaev, J. R. Mayers et al., "Reducing endoplasmic reticulum stress through a macrophage lipid 
chaperone alleviates atherosclerosis," Nature Medicine, vol. 15, no. 12, pp. 1383-1391, 2009.

[51] K. Tveten, Ø. L. Holla, T. Ranheim, K. E. Berge, T. P. Leren, and M. A. Kulseth, "4-Phenylbutyrate restores the functionality of a misfolded mutant low-density lipoprotein receptor," FEBS Journal, vol. 274, no. 8, pp. 1881-1893, 2007.

[52] K. Ono, M. Ikemoto, T. Kawarabayashi et al., "A chemical chaperone, sodium 4-phenylbutyric acid, attenuates the pathogenic potency in human $\alpha$-synuclein A30P + A53T transgenic mice," Parkinsonism and Related Disorders, vol. 15, no. 9, pp. 649-654, 2009.

[53] A. Ricobaraza, M. Cuadrado-Tejedor, A. Pérez-Mediavilla, D. Frechilla, J. Del Río, and A. García-Osta, "Phenylbutyrate ameliorates cognitive deficit and reduces tau pathology in an alzheimer's disease mouse model," Neuropsychopharmacology, vol. 34, no. 7, pp. 1721-1732, 2009.

[54] W. Qi, J. Mu, Z. F. Luo et al., "Attenuation of diabetic nephropathy in diabetes rats induced by streptozotocin by regulating the endoplasmic reticulum stress inflammatory response," Metabolism, vol. 60, no. 5, pp. 594-603, 2011.

[55] G. S. Zode, M. H. Kuehn, D. Y. Nishimura et al., "Reduction of ER stress via a chemical chaperone prevents disease phenotypes in a mouse model of primary open angle glaucoma," Journal of Clinical Investigation, vol. 121, no. 9, pp. 3542-3553, 2011.

[56] S. W. Brusilow and N. E. Maestri, "Urea cycle disorders: diagnosis, pathophysiology, and therapy," Advances in pediatrics, vol. 43, pp. 127-170, 1996.

[57] C. Xiao, A. Giacca, and G. F. Lewis, "Sodium phenylbutyrate, a drug with known capacity to reduce endoplasmic reticulum stress, partially alleviates lipid-induced insulin resistance and $\beta$-cell dysfunction in humans," Diabetes, vol. 60, no. 3, pp. 918-924, 2011. 


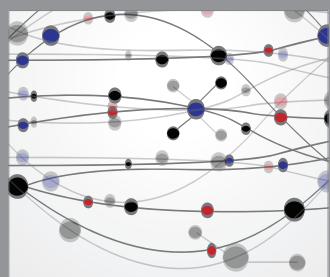

The Scientific World Journal
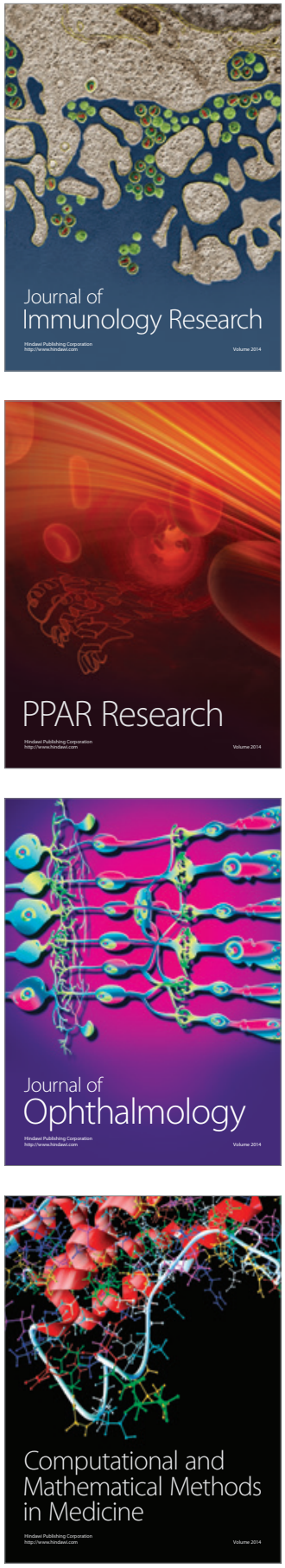

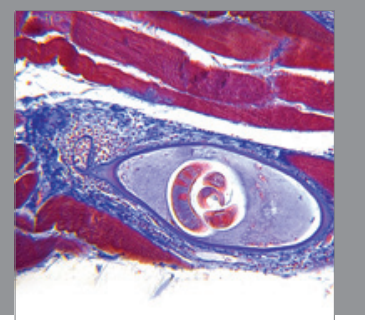

Gastroenterology

Research and Practice
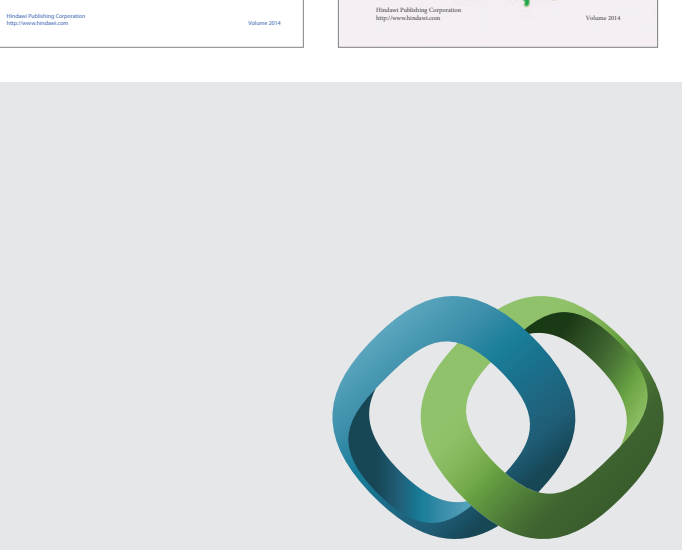

\section{Hindawi}

Submit your manuscripts at

http://www.hindawi.com
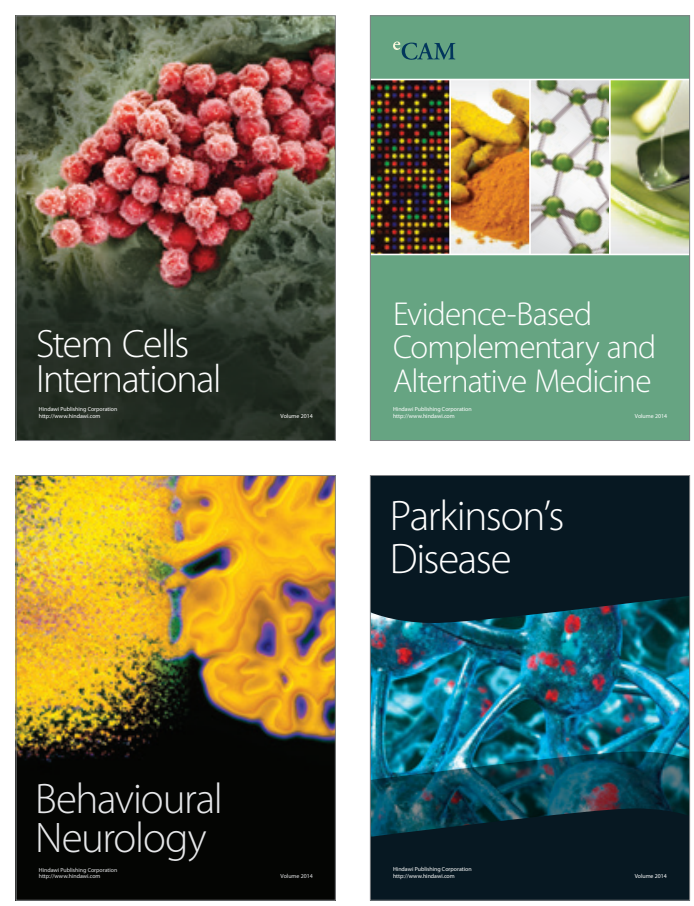

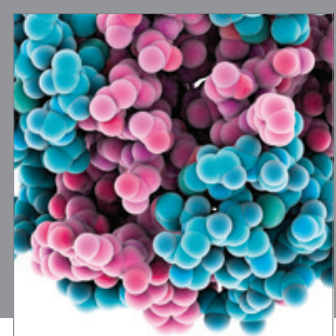

Journal of
Diabetes Research

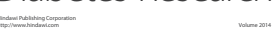

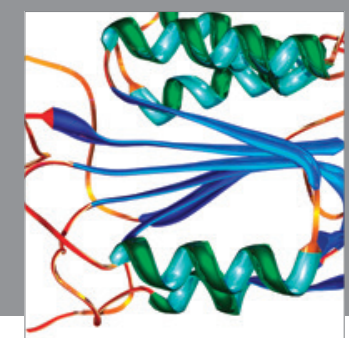

Disease Markers
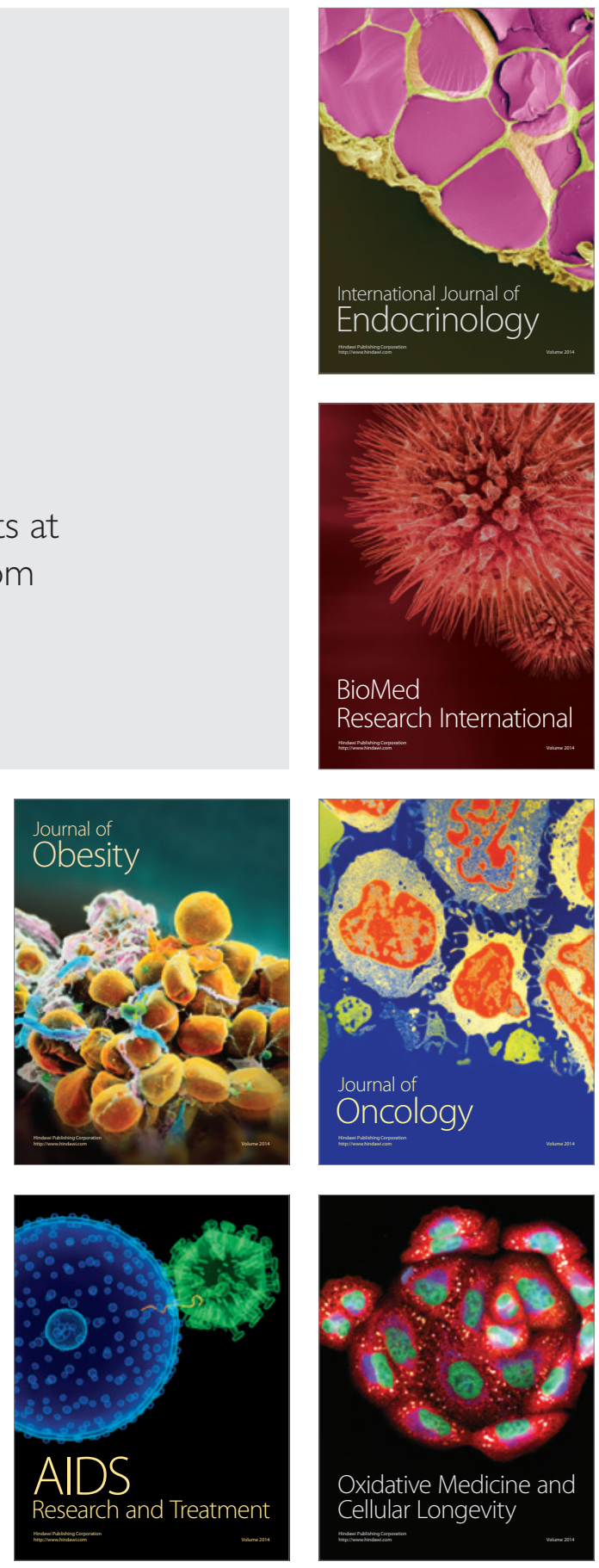